\title{
Comparison of the efficiency of subconjunctival aflibercept ranibizumab and bevacizumab in corneal neovascularization in a rat model
}

\author{
Sücattin IIlker Kocamış', Mehmet Erol Cann2, Güllçin Güler Şimşek ${ }^{3}$, Hasan Basri Çakmak \\ ${ }^{1}$ Department of Ophthalmology, Yenikent State Hospital, Sakarya, Turkey \\ ${ }^{2}$ Department of Ophthalmology, Bursa City Hospital, Bursa, Turkey \\ ${ }^{3}$ Department of Pathology, Keçiören Training and Research Hospital, Ankara, Turkey \\ ${ }^{4}$ Department of Ophthalmology, Hitit University Medical School, Çorum, Turkey
}

\begin{abstract}
BACKGROUND: Corneal neovascularization $(\mathrm{CN})$ might be a sight-threatening condition via reducing the corneal transparency. One of the most significant proangiogenic factors is vascular endothelial growth factor (VEGF) that is shown to be upregulated in CN. Accordingly, we aimed to evaluate and compare the effectiveness of aflibercept, ranibizumab, and bevacizumab in $\mathrm{CN}$ in a rat model.

MATERIAL AND METHODS: Twenty-eight male Wistar-Albino rats were administered general anesthesia. 2-mm-diameter central burns were formed on the corneas. Rats were divided into four groups randomly, and one group was administered subconjunctival saline solution as the control group. Subconjunctival aflibercept, bevacizumab, and ranibizumab were applied to the other three groups, respectively. Three rats from each group were randomly selected, and digital photographs of the corneas were taken under general anesthesia. Then, rats were euthanized, and eyes were enucleated one week and one month after the corneal injury. Three enucleated eyes from each group were prepared for histological evaluation with hematoxylin and eosin.

RESULTS: According to the first week results, there was no central CN in all groups except the control group. There was no statistically significant difference in total $\mathrm{CN}$ among the groups according to the Kruskal-Wallis test $(\mathrm{p}=$ 0.09). The control group had a higher inflammation score than the other groups in the central cornea. On the other hand, the control group had less intense fibrosis than the other groups in the central cornea. In the first month, there was a spontaneous regression in central $\mathrm{CN}$ in the control group. There was again no statistical difference among the groups regarding the $\mathrm{CN}(\mathrm{p}=0.46)$. There was no inflammation in the central cornea in any groups.

CONCLUSION: Single-dose subconjunctival injection of aflibercept, ranibizumab, and bevacizumab prevents the central $\mathrm{CN}$ and reduces the inflammation.
\end{abstract}

KEY WORDS: aflibercept; bevacizumab; corneal neovascularization; ranibizumab

Ophthalmol J 2021; Vol. 6, 155-160

CORRESPONDING AUTHOR:

Sücattin Ilker Kocamış, Department of Ophthalmology, Yenikent State Hospital, Sakarya, Turkey, 509. Sok. No:17A/5 Serdivan, Sakarya, tel:+905336821669; email: drilkerkocamis@gmail.com 


\section{INTRODUCTION}

Corneal neovascularization $(\mathrm{CN})$ might be a sight-threatening condition via reducing the corneal transparency and/or causing refractive errors. The cornea has an equilibrium between the proangiogenic and antiangiogenic factors, which can be disrupted by trauma, infection, inflammation, and hypoxia [1]. One of the most significant proangiogenic factors is Vascular Endothelial Growth Factor (VEGF) that was shown to be upregulated in $\mathrm{CN}$ [2]. Therefore, anti-VEGF molecules have been considered as potential candidates for $\mathrm{CN}$ treatment [3].

Bevacizumab is a humanized monoclonal antibody that selectively antagonizes all isoforms of VEGF-A and has been extensively used off-label in ophthalmology [4]. Ranibizumab is a similar molecule to bevacizumab that is generated for ophthalmic use, including only Fab without Fc domain and having a smaller molecular weight. Aflibercept is a VEGF trap that binds all VEGF$\mathrm{A}$ isoforms, VEGF-B, and placental growth factors 1 and 2 . In age-related macular degeneration treatment, aflibercept is considered the highest affinity VEGF blocker and more potent than ranibizumab and bevacizumab [5]. To date, various studies investigating and comparing the efficiency of these anti-VEGFs have been performed in animal models with conflicting results [6-8]. However, there is no study including all three together in an animal model yet. Accordingly, we aimed to evaluate and compare the effectiveness of aflibercept, ranibizumab, and bevacizumab in $\mathrm{CN}$ in a rat model.

\section{MATERIAL AND METHODS}

This study was approved by the Gazi University Animal Experiments Local Ethics Committee (No: G.Ü.ET-15.055). All the protocols of the ARVO Statement for the Use of Animals in Ophthalmic and Vision Research were followed. Twenty-eight male Wistar-Albino rats weighing between 250-350 grams with healthy clear corneas were administered general anesthesia via intramuscular $50 \mathrm{mg} / \mathrm{kg}$ body weight ketamine hydrochloride and $5 \mathrm{mg} / \mathrm{kg}$ xylazine. Topical $0.5 \%$ proparacaine hydrochloride eye drops were applied before the chemical burns were formed on the right eyes of each rat. The corneas were exposed to a stick covered with $75 \%$ silver nitrate and $25 \%$ potassium nitrate for 10 seconds to create a $2 \mathrm{~mm}$ diameter central burn (Fig. 1). Then, eyes were irrigated with

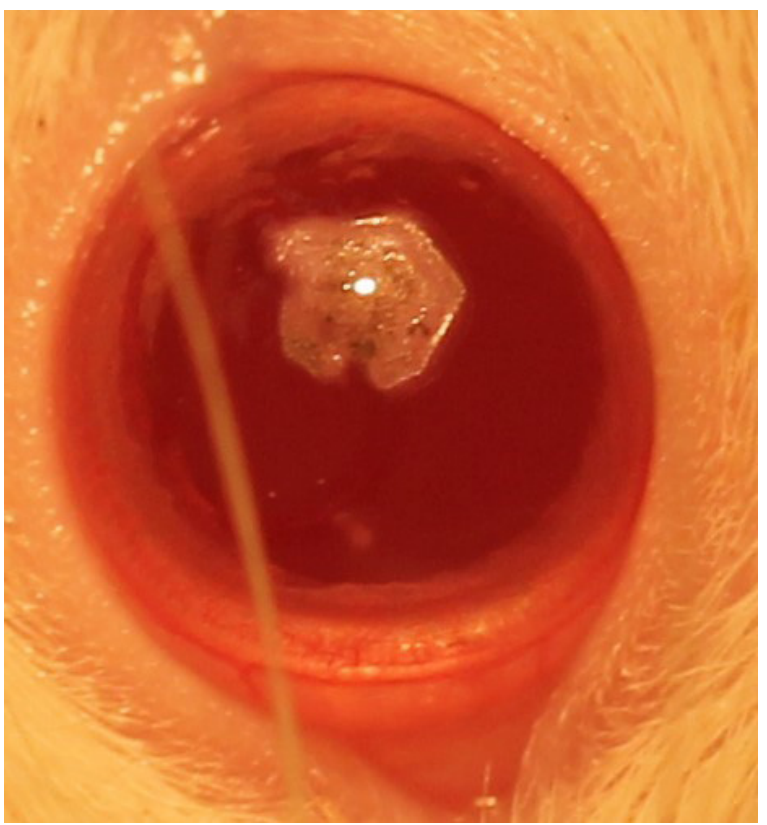

FIGURE 1. Central corneal burn

$5 \mathrm{ml}$ balanced salt solution for 1 minute. Rats were divided into four groups randomly, and one group was administered subconjunctival saline solution $(0.05 \mathrm{~mL})$ as the control group. Subconjunctival aflibercept $2 \mathrm{mg}(0.05 \mathrm{~mL})$, bevacizumab $1.25 \mathrm{mg}$ $(0.05 \mathrm{~mL})$ and ranibizumab $0.5 \mathrm{mg}(0.05 \mathrm{~mL})$ were applied to other three groups respectively.

Three rats from each group were randomly selected, and digital photographs of the corneas were taken under general anesthesia. Then, rats were euthanized, and eyes were enucleated. This procedure was carried out one week and one month after the corneal injury.

After three enucleated eyes from each group were fixated with $10 \%$ formaldehyde for 24 hours, limbus to limbus corneal sections, including the most dense neovascularized corneal areas, were excised. These sections were dehydrated and embedded in paraffin blocks. From the sections, $5 \mu \mathrm{m}$ thickness sagittal cuts were made with microtomes and prepared for hematoxylin and eosin staining. The stained vessels were counted under the light microscope with $\times 400$ magnification and then compared using the Kruskal-Wallis test. Also, sections were evaluated regarding the inflammation based on the inflammation scale described before (1: focal fibroblast activity and focal a few mixed type inflammatory cells, 3: diffuse and intense fibroblast activity and lots of mixed types inflammatory cells, 2: between 1 and 3) [9]. The results were presented with column bars. 


\section{RESULTS}

According to the first week results, there was no central $\mathrm{CN}$ in all the groups except the control group (Fig. 2, 3). There was no statistically significant difference in total $\mathrm{CN}$ among the groups $(\mathrm{p}=0.09)$ (Tab. 1). The control group had a higher inflammation score than the other groups in the central cornea. On the other hand, the control group had less intense fibrosis than the other groups in the central cornea (Fig. 4).

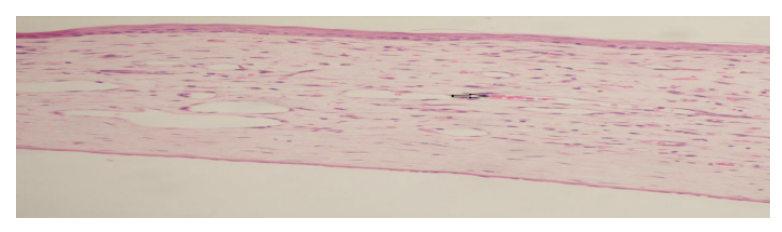

FIGURE 2. Control group staining with hematoxylin and eosin. Arrow showing vessel lumen involving erythrocytes in central cornea
After the first month, there was a spontaneous regression in central $\mathrm{CN}$ in the control group. Again, there was no statistical difference among the groups regarding the $\mathrm{CN}$ ( $\mathrm{p}=0.46$ ) (Tab. 2). There was no inflammation in the central cornea in any groups. There was no fibrosis in the aflibercept group in the central cornea at the first month. Other groups had grade 1 and more fibrosis scores.

\section{DISCUSSION}

Our study indicated that early anti-VEGF treatment is effective in preventing central $\mathrm{CN}$ after corneal insult. There was no central $\mathrm{CN}$ in all treatment groups at one week and one month after the corneal injury. The $\mathrm{CN}$ presented in the control group at the first week was regressed one month after the injury. This possible spontaneous regression was demonstrated in rat corneas [10]. Although there was no statistically significant

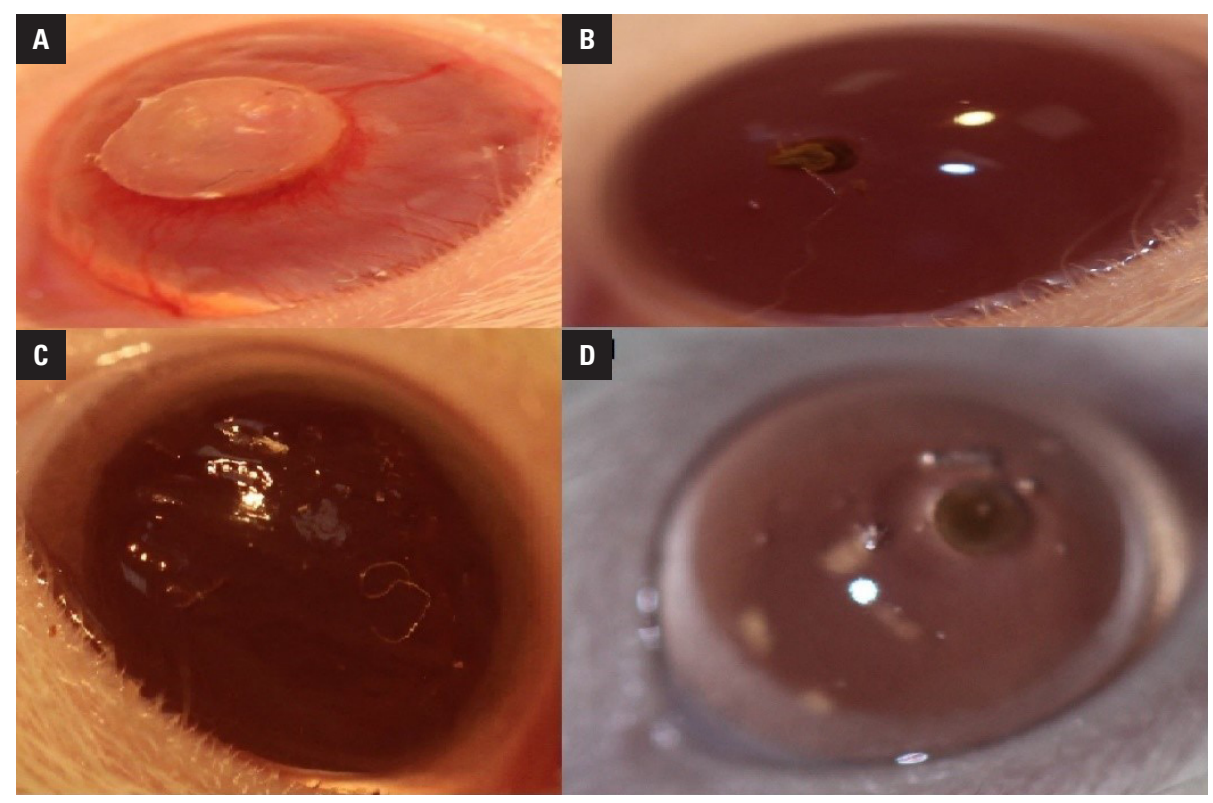

FIGURE 3. Cornea photographs of the control group (A) bevacizumab group (B) aflibercept group (C) ranibizumab group (D) at the first week

Table 1. Vessel counts in histological specimens between the groups at the first week (Kruskal-Wallis test)

\begin{tabular}{|l|c|c|c|c|c|c|c|}
\hline Groups & Number & Mean & $\begin{array}{c}\text { Standard } \\
\text { deviation }\end{array}$ & Median & Minimum & Maximum & p \\
\hline Control & 3 & 16.3333 & 6.02771 & 17.0000 & 10.00 & 22.00 & 0.090 \\
\hline Ranibizumab & 3 & 12.3333 & 3.78594 & 14.0000 & 8.00 & 15.00 & \\
\hline Aflibercept & 3 & 6.3333 & 1.52753 & 6.0000 & 5.00 & 8.00 & \\
\hline Bevacizumab & 3 & 10.6667 & 4.04145 & 10.0000 & 7.00 & 15.00 & \\
\hline
\end{tabular}




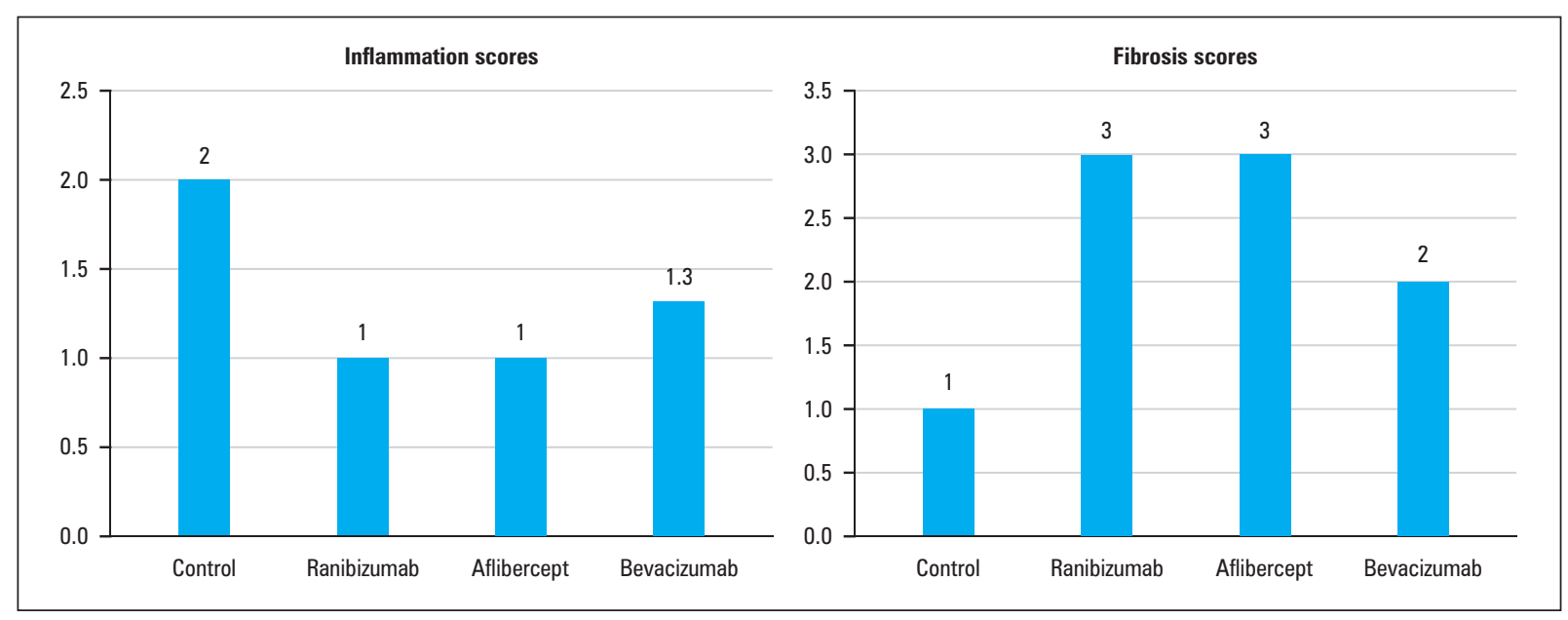

FIGURE 4. Inflammation and fibrosis scores of the groups at the first week

\begin{tabular}{|l|c|c|c|c|c|c|c|}
\hline Table 2. Vessel counts in histological specimens between the groups at the first month (Kruskal-Wallis test) \\
\hline Groups & Number & Mean & $\begin{array}{c}\text { Standard } \\
\text { deviation }\end{array}$ & Median & Minimum & Maximum & p \\
\hline Control & 3 & 12.00 & 3.61 & 13.0000 & 8.00 & 15.00 & 0.464 \\
\hline Ranibizumab & 3 & 15.33 & 4.04 & 13.0000 & 13.00 & 20.00 & \\
\hline Aflibercept & 3 & 15.00 & 5.00 & 15.0000 & 10.00 & 20.00 & \\
\hline Bevacizumab & 3 & 10.67 & 2.89 & 9.0000 & 9.00 & 14.00 & \\
\hline
\end{tabular}

difference in vessel counts among the groups in histological evaluation at the first week, we think that this result was due to small number of the groups, and the difference between the groups was clinically significant. However, this statistical insignificancy was higher at the first month. This result might have arisen from the single-dose treatment and probable short-term therapeutical effect of anti-VEGFs. It is possible that low-dose anti-VEGF treatment can inhibit only early vessel formation and may be insufficient to prevent the late-term $\mathrm{CN}$. This theory was supported by earlier studies indicating that bevacizumab was ineffective in preventing late-formed $\mathrm{CN}$ in experimental animal models $[11,12]$. Also, it was demonstrated that repeated doses of subconjunctival or topical treatments had better outcomes in reducing early and late formed CN $[13,14]$.

One of the purposes of this study was to compare the efficacy of aflibercept, ranibizumab, and bevacizumab in CN treatment. Despite the fact that we couldn't apply the Bonferroni test to analyze the differences between the two groups as the Kruskal-Wallis test did not demonstrate a statistically significant difference among the groups, we could observe that the aflibercept group had the lesser amount of vessel count in specimens one week after the treatment. However, there was no difference between any groups after one month. In a comparative rat study comprising the subconjunctival bevacizumab and ranibizumab, it was found that the bevacizumab group had less $\mathrm{CN}$ intensity than the ranibizumab group on the 8 th day regarding the histological evaluation. Moreover, there was not a statistically significant difference between the ranibizumab and control group [9]. On the other hand, in another experimental animal model, there was no difference between subconjunctival bevacizumab and ranibizumab seven days after the treatment regarding their inhibitory effect in CN [15]. Gal-Or et al. conducted a study comparing the inhibitory effects of subconjunctival aflibercept and bevacizumab in an experimental rat $\mathrm{CN}$ model. They showed that aflibercept prevented central $\mathrm{CN}$ formation contrary to bevacizumab. They stated that this result might be due to insufficiency of single-dose bevacizumab injection or the impact of other proangiogenic factors in $\mathrm{CN}$ other than VEGF-A, like placental growth factor 1 and 2 which beva- 
cizumab couldn't inhibit contrary to aflibercept. They indicated that a possible stronger interaction between the aflibercept and rodent VEGF-A than bevacizumab and rodent VEGF-A might cause this outcome [16]. Moreover, similar outcomes were reached when topical aflibercept and bevacizumab were compared again in an experimental rat $\mathrm{CN}$ model [17].

At the first week, there was less inflammation involving the central cornea in treatment groups compared to the control group in our study. On the contrary, the control group had less fibrosis involving the central cornea than the treatment groups. The former result is expected as VEGF increases vascular permeability and helps the transportation of inflammatory cells. Also, certain previous studies confirmed this result $[18,19]$. The unexpected latter result can be explained by the theory that even though VEGF has a role in preventing fibrosis, it also has a role in fibrosis resolution [20]. Therefore, we think that anti-VEGF treatment may decrease the fibrosis resolution which is required for an already formed corneal insult. At the first month, there was no inflammation in the central cornea in any groups indicating that the activity of the inflammatory factors had already been finished and the fibrosis had already been established before the first month after the corneal insult.

\section{CONCLUSION}

Single-dose subconjunctival injection of aflibercept, ranibizumab, and bevacizumab prevents the central CN. Aflibercept seems to be superior to bevacizumab and ranibizumab in inhibiting the $C N$. However, there is no difference between ranibizumab and bevacizumab. Repeated dose anti-VEGF injections could be more effective in preventing the total $\mathrm{CN}$.

\section{Acknowledgements}

This study was supported from Hitit University Scientific Research Department. Project No: TIP19002.15

\section{Conflict of interest}

There is no conflict of interest.

\section{REFERENCES}

1. Azar DT. Corneal angiogenic privilege: angiogenic and antiangiogenic factors in corneal avascularity, vasculogenesis, and wound healing (an American Ophthalmological Society thesis). Trans Am Ophthalmol Soc. 2006; 104: 264-302, indexed in Pubmed: 17471348.
2. Philipp W, Speicher L, Humpel C. Expression of vascular endothelial growth factor and its receptors in inflamed and vascularized human corneas. Invest Ophthalmol Vis Sci. 2000; 41(9): 2514-2522, indexed in Pubmed: 10937562.

3. Nicholas MP, Mysore N. Corneal neovascularization. Exp Eye Res. 2021; 202: 108363, doi: 10.1016/j.exer.2020.108363, indexed in Pubmed: 33221371.

4. Avery RL, Pieramici DJ, Rabena MD, et al. Intravitreal bevacizumab (Avastin) for neovascular age-related macular degeneration. Ophthalmology. 2006; 113(3): 363-372.e5, doi: 10.1016/j. ophtha.2005.11.019, indexed in Pubmed: 16458968.

5. Sarwar S, Clearfield E, Soliman MK, et al. Aflibercept for neovascular age-related macular degeneration. Cochrane Database Syst Rev. 2016; 2: CD011346, doi: 10.1002/14651858.CD011346.pub2, indexed in Pubmed: 26857947.

6. Dursun A, Arici MK, Dursun F, et al. Comparison of the effects of bevacizumab and ranibizumab injection on corneal angiogenesis in an alkali burn induced model. Int J Ophthalmol. 2012; 5(4): 448-451, doi: 10.3980/j. issn.2222-3959.2012.04.08, indexed in Pubmed: 22937503.

7. Ahmed A, Berati $H$, Nalan A, et al. Effect of bevacizumab on corneal neovascularization in experimental rabbit model. Clin Exp Ophthalmol. 2009; 37(7): 730-736, doi: 10.1111/j.1442-9071.2009.02112.x, indexed in Pubmed: 19788671.

8. Eiger-Moscovich M, Livny E, Sella R, et al. Comparison of Subconjunctival Aflibercept and Betamethasone for the Treatment of Formed Corneal Neovascularization in a Rabbit Model. Ophthalmic Res. 2019; 62(2): 116-122, doi: 10.1159/000499165, indexed in Pubmed: 31112967.

9. Sener E, Yuksel N, Yildiz DK, et al. The impact of subconjuctivally injected EGF and VEGF inhibitors on experimental corneal neovascularization in rat model. Curr Eye Res. 2011; 36(11): 1005-1013, doi: 10.3109/02713683.2011.601840, indexed in Pubmed: 21999227.

10. Edelman JL, Castro MR, Wen Y. Correlation of VEGF expression by leukocytes with the growth and regression of blood vessels in the rat cornea. Invest Ophthalmol Vis Sci. 1999; 40(6): 1112-1123, indexed in Pubmed: 10235544.

11. Kang S, Chung SK. The effect of subconjuctival combined treatment of bevacizumab and triamcinolone acetonide on corneal neovascularization in rabbits. Cornea. 2010; 29(2): 192-196, doi: 10.1097/ IC0.0b013e3181b1c82f, indexed in Pubmed: 20098156.

12. Ulas B, Altan-Yaycioglu R, Bal N. Comparison of the inhibitory effect of different doses of subconjunctival bevacizumab application in an experimental model of corneal neovascularization. Int $\mathrm{J}$ Ophthalmol. 2018; 11(7): 1090-1095, doi: 10.18240/ijo.2018.07.03, indexed in Pubmed: 30046522.

13. Chen WL, Chen YM, Chu HS, et al. Mechanisms controlling the effects of bevacizumab (avastin) on the inhibition of early but not late formed corneal neovascularization. PLoS One. 2014; 9(4): e94205, doi: 10.1371/journal.pone.0094205, indexed in Pubmed: 24714670.

14. Lin CT, Hu FR, Kuo KT, et al. The different effects of early and late bevacizumab (Avastin) injection on inhibiting corneal neovascularization and conjunctivalization in rabbit limbal insufficiency. Invest Ophthalmol Vis Sci. 2010; 51(12): 6277-6285, doi: 10.1167/iovs.09-4571, indexed in Pubmed: 20435600.

15. Kim EK, Kong SJ, Chung SK. Comparative study of ranibizumab and bevacizumab on corneal neovascularization in rabbits. Cornea. 2014; 33(1): 60-64, doi: 10.1097/IC0.0000000000000007, indexed in Pubmed: 24240485.

16. Gal-Or O, Livny E, Sella R, et al. Efficacy of Subconjunctival Aflibercept Versus Bevacizumab for Prevention of Corneal Neovascularization in a Rat Model. Cornea. 2016; 35(7): 991-996, doi: 10.1097/ IC0.0000000000000849, indexed in Pubmed: 27124775.

17. Sella R, Gal-Or O, Livny E, et al. Efficacy of topical aflibercept versus topical bevacizumab for the prevention of corneal neovascularization in a rat model. Exp Eye Res. 2016; 146: 224-232, doi: 10.1016/j. exer.2016.03.021, indexed in Pubmed: 27020759.

18. Kadar T, Amir A, Cohen L, et al. Anti-VEGF therapy (bevacizumab) for sulfur mustard-induced corneal neovascularization associated with delayed limbal stem cell deficiency in rabbits. Curr Eye Res. 2014; 39(5): 439-450, doi: 10.3109/02713683.2013.850098, indexed in Pubmed: 24215293. 
19. Oh JY, Kim MK, Shin MiS, et al. The anti-inflammatory effect of subconjunctival bevacizumab on chemically burned rat corneas. Curr Eye Res. 2009; 34(2): 85-91, doi: 10.1080/02713680802607740, indexed in Pubmed: 19219678.
20. Yang L, Kwon J, Popov Y, et al. Vascular endothelial growth factor promotes fibrosis resolution and repair in mice. Gastroenterology. 2014; 146(5): 1339-13350.e1, doi: 10.1053/j.gastro.2014.01.061, indexed in Pubmed: 24503129. 